\title{
Simethicone administration improves gastric cleanness for esophagogastroduodenoscopy: a randomized clinical trial
}

Xiaotian Sun ${ }^{1,2+} \mathbb{D}$, Yang $\mathrm{Xu}^{1 \dagger}$, Xueting Zhang ${ }^{1 \dagger}$, Cuiyun $\mathrm{Ma}^{1}$, Aitong $\mathrm{Li}^{1}$, Haiyan $\mathrm{Yu}^{1}$, Weihua Zhang ${ }^{1}$, Hanqing Zhang ${ }^{1}$, Teng Yang ${ }^{1}$, Xinfang Miao ${ }^{3}$, Huiming Zhang ${ }^{3}$, Yan Liu ${ }^{1}$ and Zheng Lư ${ }^{4^{*}}$

\begin{abstract}
Background: Esophagogastroduodenoscopy is very useful in diagnosing and treating upper gastrointestinal mucosal disorders, but too much foam and water in stomach decrease its diagnostic efficiency. Simethicone administration can help remove excessive foam.

Aims: To determine the optimal simethicone administration strategies in a comparative randomized controlled clinical trial.

Methods: Adult outpatients with indications for esophagogastroduodenoscopy were enrolled and randomly divided into group 1 (simethicone solution intake 20-30 min before procedure, $n=110$ ), group 2 (simethicone solution intake 31-60 min before procedure, $n=92$ ), and group 3 (simethicone solution intake $>60$ min before procedure). Primary and secondary outcomes were procedure time and the patients' satisfaction after the examination. All symptoms like abdominal pain and distension were recorded.
\end{abstract}

Results: No statistically significant differences were found on the patients' demographic and clinical features and mean examination time (all $P$ values $>0.05$ ). The distribution of patients with different endoscopic and pathological diagnosis was comparable among three groups, respectively $(P=0.607 ; P=0.289)$. However, the proportion of patients with Gastric Cleanness Grade A was most in group $2(n=73,79.3 \%)$, and patient proportion with Gastric Cleanness Grade $C$ was most found in group $1(n=72,65.5 \%)$, which was greatly different $(P<0.001)$. There was no statistically significant difference on the satisfaction scores [immediately $6(3-8)$ vs. $6(1-10)$ vs. $6(1-9), P=0.533$; $2 \mathrm{~h}$ after 10 (8-10) vs. 10 (10-10) vs. $10(8-10), P=0.463]$.

Conclusion: Simethicone solution intake 31-60 min before esophagogastroduodenoscopy can help obtain the best gastric cleanness, which is recommended in clinical practice (registered at ClinicalTrials.gov, NCT03776916 on December 13, 2018).

Keywords: Esophagogastroduodenoscopy, Stomach, Simethicone, Diagnosis

\footnotetext{
* Correspondence: 13818223446@163.com

${ }^{+}$Xiaotian Sun, Yang Xu, and Xueting Zhang contributed equally to this work. ${ }^{4}$ Department of Hepatology, The Fifth Medical Center of Chinese PLA

General Hospital, No. 100 Middle Road in Fourth West Ring, Beijing 100039,

China

Full list of author information is available at the end of the article
}

C C The Author(s). 2021 Open Access This article is licensed under a Creative Commons Attribution 4.0 International License, which permits use, sharing, adaptation, distribution and reproduction in any medium or format, as long as you give appropriate credit to the original author(s) and the source, provide a link to the Creative Commons licence, and indicate if changes were made. The images or other third party material in this article are included in the article's Creative Commons licence, unless indicated otherwise in a credit line to the material. If material is not included in the article's Creative Commons licence and your intended use is not permitted by statutory regulation or exceeds the permitted use, you will need to obtain permission directly from the copyright holder. To view a copy of this licence, visit http://creativecommons.org/licenses/by/4.0/ The Creative Commons Public Domain Dedication waiver (http://creativecommons.org/publicdomain/zero/1.0/) applies to the data made available in this article, unless otherwise stated in a credit line to the data. 


\section{What is known?}

The presence of too much foam and water in the stomach limited esophagogastroduodenoscopy's value in managing upper gastrointestinal mucosal disorders. Simethicone can remove excessive foam, while its optimal administration strategy has not been examined.

\section{What is new here?}

Simethicone solution intake 31-60 min before esophagogastroduodenoscopy can effectively help obtain the best gastric cleanness for upper gastrointestinal endoscopy, which can be recommended as a routine in clinical practice.

\section{Introduction}

Esophagogastroduodenoscopy is well acknowledged as the most useful tool for diagnosing and treating upper gastrointestinal tract mucosal lesions $[1,2]$. It has the advantage of directly observing the esophageal, gastric, and duodenal mucosa and obtaining biopsy of the potential lesions for pathological examination, thus being widely applied in clinical practice all over the world [3-5]. However, during the examination, too much water, mucus, foam, or residues in the stomach will not only increase the procedure time and the misdiagnosis rate, but also decrease the patients' tolerance, so more efforts should be made to avoid excessive water, mucus, foam or residues in order to get a clear view of the upper gastrointestinal tract mucosa.

Simethicone is also called poly-dimethylsiloxane, which has been introduced to remove the foam and water. Recent studies have reported that the administration of simethicone before endoscopic examination could shorten the procedure time and improve the diagnostic rate of the gastric mucosal lesions $[6,7]$. Although simethicone has been routinely administrated before the esophagogastroduodenoscopy, the optimal strategy of administrating simethicone has not been clearly investigated, especially the time interval from simethicone administration to the endoscopic procedure. Too late intake of simethicone will result in too excessive water in the stomach due to the insufficient time for the stomach to empty, while if the patients take it too early, it does not take effects. Thus, we conducted this randomized controlled clinical trial aiming to optimize the current simethicone administration strategies, and these results could improve the performance of the esophagogastroduodenoscopy and minimize the patients' dissatisfaction. Different simethicone administration strategies for esophagogastroduodenoscopy were compared and whether the time of taking simethicone before endoscopy could influence the efficacy and efficiency of the endoscopic examination was tested, which may benefit the identification of a standardized protocol for endoscopic procedures.

\section{Patients and methods Patients}

Adult outpatients with the indications for esophagogastroduodenoscopy who agreed to participate in the study in Endoscopy Center of the Fifth Medical Center of Chinese PLA General Hospital from December 17, 2018, to March 17, 2019, were included. Patients who were receiving nonsteroidal anti-inflammatory drugs, pump inhibitors (PPI), or antibiotics in the last 3 weeks or had severe uncontrolled coagulopathy, prior history of gastric surgery, or were pregnant and lactation were excluded. All the patients signed written informed consent, which was obtained by the main researcher. The main researcher enrolled the participants and assigned the interventions.

\section{Study design and grouping}

The flow chart was shown in Fig. 1. This study was registered at ClinicalTrials.gov on December 13, 2018, and the registration number was NCT03776916 (https:// www.clinicaltrials.gov/ct2/show/NCT03776916?term= NCT03776916\&draw=1\&rank=1). The protocol was approved by the ethic committee of Affiliated Hospital to Chinese Academy of Military Medical Sciences (the Fifth Medical Center of Chinese PLA General Hospital) on October 12, 2018.

The sample size was calculated to reveal a difference on the gastric cleanness among different groups, keeping a power of 0.9 and significance level alpha of 0.05 . Considering that the dropout rate was around $20 \%$, the sample size was estimated to be 300 . All the patients were randomly divided into three experimental groups using random number method: group 1 (simethicone solution intake 20-30 min before the procedure, $n=110$ ), group 2 (simethicone solution intake 31-60 min before the procedure, $n=92$ ), and group 3 (simethicone solution intake $>60 \mathrm{~min}$ before the procedure, $n=109$ ). An independent researcher who was not involved in the study generated the random allocation sequence, which was stored in sealed envelopes. The envelopes were opened only the randomization was conducted. An independent researcher assistant was responsible for the data collection and management, and all the data were categorized and analyzed based on an electronic datasheet. Another senior researcher was responsible for monitoring and auditing the study. The patients and endoscopists were blinded to the grouping.

\section{Esophagogastroduodenoscopy}

All endoscopic procedures were completed by one experienced expert endoscopist who had an endoscopy 


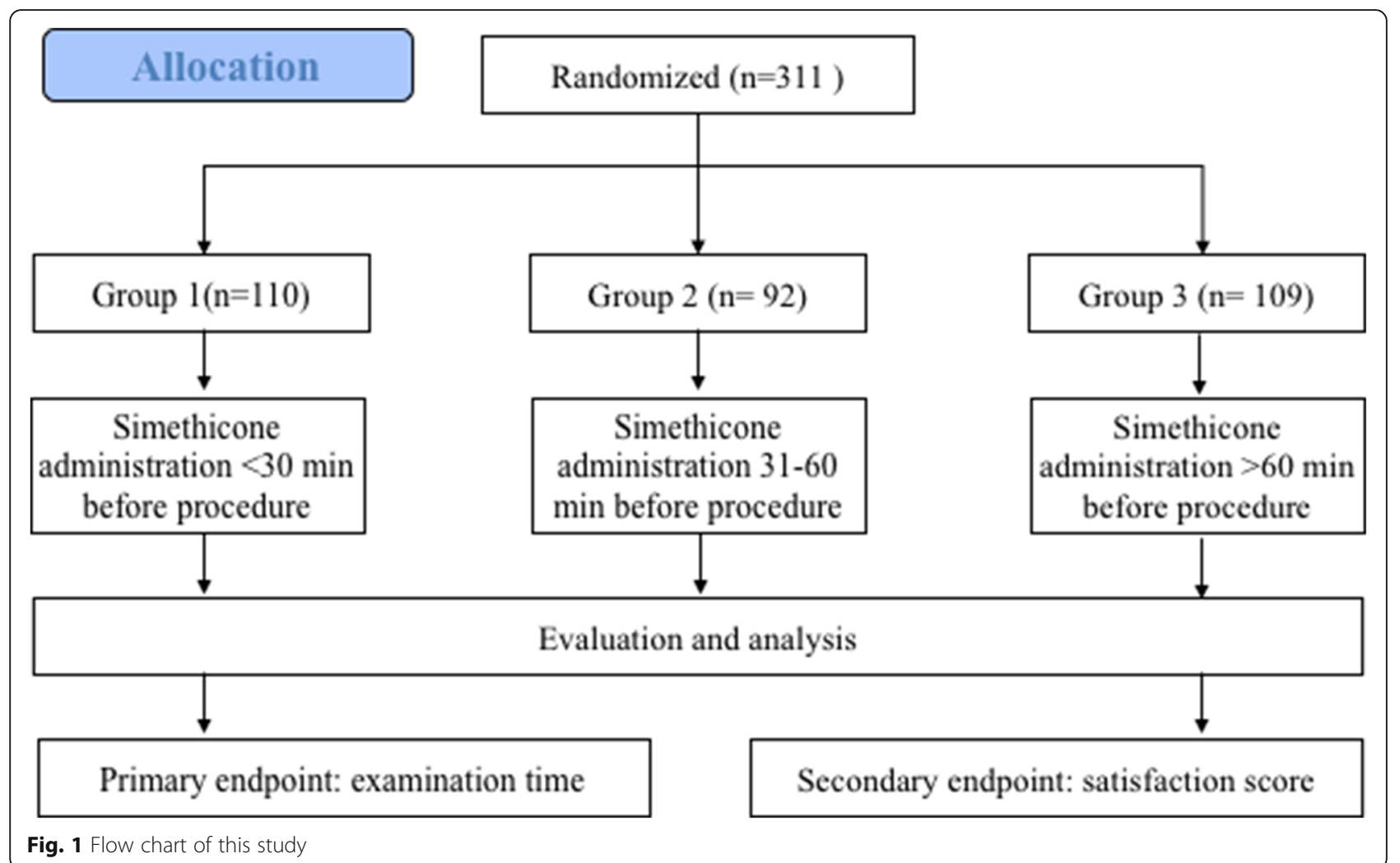

experience of over 5 years. No patients underwent propofol sedation. EG-L590WR endoscopes equipped with the LASEREO endoscopic system (FUJIFILM Co., Tokyo, Japan) were used. The gastric cleanness was evaluated by the endoscopist as Gastric Cleanness Grade and categorized into 3 grades based on the findings of the stomach (Fig. 2). All the endoscopic images taken during the esophagogastroduodenoscopy were evaluated, and the percentage of water and foam in each image was assessed as a subjective evaluator for Gastric Cleanness Grade. After the procedure, all patients were routinely monitored for $1 \mathrm{~h}$.

\section{Outcomes}

Primary outcome was procedure time. The time of examining the whole stomach was recorded, and the time for biopsy was not included. Secondary outcome was the patients' satisfaction after the examination. A 10-point scale was used to evaluate the patients' satisfaction ( 0 worst, 10 best). All the symptoms such as abdominal pain, distension, and unintended effects were also recorded.

\section{Statistical analysis}

All the statistical analysis was performed using SPSS software. The continuous and categorical data were presented as mean (range) and percentage, respectively. The differences among three groups were tested by one-way analysis of variance (ANOVA) and chi-square if applicable. A two-tailed $P$ value less than 0.05 was considered as statistically significant.

\section{Results}

Demographic and clinical characteristics

A total of 311 patients were included for analysis, including 110 in group 1, 92 in group 2, and 109 in group 3 . There were no statistically significant differences on the demographic (age and gender) and clinical features (previous esophagogastroduodenoscopy history, indications for endoscopic examinations and positive $\mathrm{H}$. pylori infection within 3 months) (all $P$ values $>0.05$ ) (Table 1 ).

\section{Endoscopic examinations}

The distribution of patients with different endoscopic and pathological diagnosis was comparable among the three groups, respectively $(P=0.607 ; P=0.289)$ (Table 2$)$. The mean examination time in groups 1,2 , and 3 was 8 (2-20), 6 (2-15), and 9 (2-25) min, which was not greatly different $(P=0.267)$.

However, statistically significant differences were found on gastric cleanness grade $(P<0.001)$ (Table 2$)$. The proportion of patients with Gastric Cleanness Grade A was most in group $2(n=73,79.3 \%)$, followed by group $3(n=29,26.6 \%)$ and then group $1(n=19$, 


\begin{tabular}{|l|l|c|}
\hline \multicolumn{2}{|c|}{ Gastric Cleanness Grade by endoscopists } & Percentage of water and foam images \\
\hline A & Litter water in fundus or foam in body & $\leq 20 \%$ \\
\hline B & Medium water or foam in fundus and/or body & $20-60$ \\
\hline C & Debris, plenty of water or foam in fundus and/or body & $\geq 60$ \\
\hline
\end{tabular}

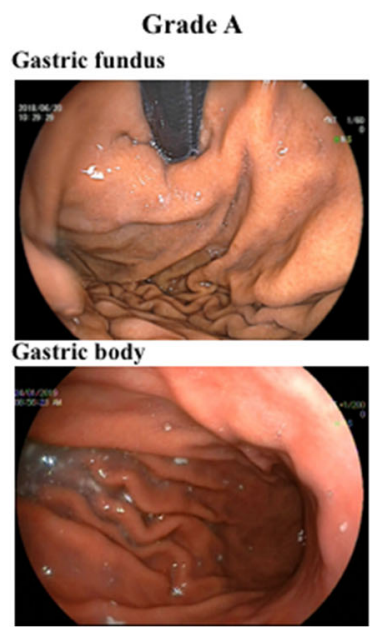

Grade B

Grade C
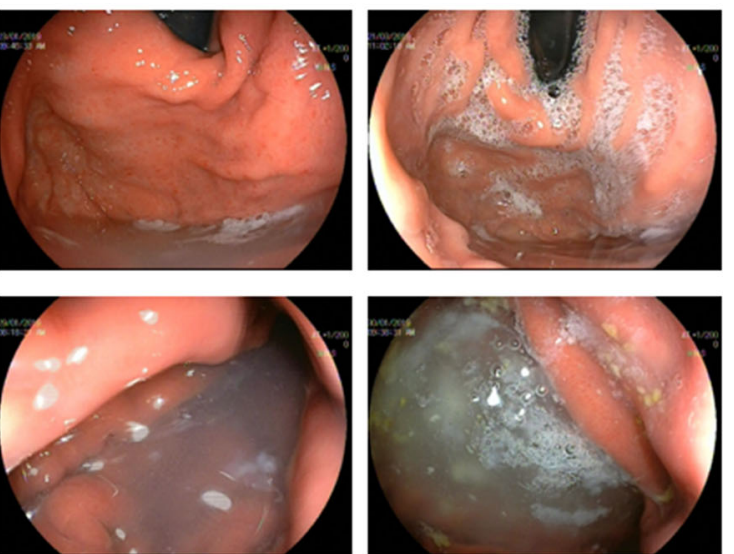

Fig. 2 Typical images of the stomach

17.3\%). Patient proportion with Gastric Cleanness Grade C was most found in group $1(n=72,65.5 \%)$, followed by group $3(n=39,35.8 \%)$ and group $2(n=7,7.6 \%)$.

\section{Patients' satisfaction}

Satisfaction score was reported by the patients immediately and $2 \mathrm{~h}$ after the endoscopic examinations, but there was no statistically significant difference on the satisfaction scores [6 (3-8) vs. $6(1-10)$ vs. $6(1-9), P=$ $0.533 ; 10(8-10)$ vs. $10(10-10)$ vs. $10(8-10), P=0.463]$ (Table 3). For discomfort reported immediately after the endoscopy, 38 patients (34.5\%) in group 1, 23 patients (25.0\%) in group 2, and 29 patients (26.6\%) in group 3 complained the presence of abdominal distension $(P=$ $0.264)$. Thirteen patients $(11.8 \%)$ in group 1,8 patients
(8.7\%) in group 2, and 6 patients (5.5\%) in group 3 had nausea $(P=0.252)$. In group $1,24.54 \%$ patients $(n=27)$ had throat pain, which was $2.2 \%(n=2)$ in group 2 and $10.8 \%(n=10)$ in group $3(P<0.001)$ (Table 3$)$.

\section{Discussion}

Esophagogastroduodenoscopy is the most useful tool for diagnosing and treating upper gastrointestinal mucosal lesions. At recent, great progress has been made on improving the efficiency and accuracy of the endoscopic procedures [8]. It is reported that the administration of simethicone before esophagogastroduodenoscopy can increase the detection rate of the lesions by removing the foams in the stomach [9]. However, the optimal strategy of simethicone usage has not been well clarified. Thus,

Table 1 Demographic and clinical characteristics

\begin{tabular}{|c|c|c|c|c|}
\hline & Group $1(n=110)$ & Group $2(n=92)$ & Group $3(n=109)$ & $P$ value \\
\hline Age, years, range & $18-88$ & $22-80$ & $23-84$ & 0.672 \\
\hline Male gender, $n(\%)$ & $56(50.9)$ & $49(53.3)$ & $43(39.5)$ & 0.102 \\
\hline Previous history of esophagogastroduodenoscopy, $n(\%)$ & $78(70.9)$ & $53(57.6)$ & $57(52.3)$ & 0.484 \\
\hline Indications, $n(\%)$ & & & & 0.331 \\
\hline Epigastric pain & $47(42.7)$ & $43(46.7)$ & $35(32.1)$ & \\
\hline Dyspepsia & $13(11.8)$ & $16(17.4)$ & $39(35.8)$ & \\
\hline Nausea & $8(7.3)$ & $3(3.3)$ & $3(2.8)$ & \\
\hline Vomit & $6(5.5)$ & $2(2.2)$ & $2(1.8)$ & \\
\hline Heartburn & $21(19.1)$ & $10(10.9)$ & $14(12.8)$ & \\
\hline Surveillance & $15(13.6)$ & $18(19.6)$ & $16(14.7)$ & \\
\hline Positive H. pylori infection within 3 months, $n$ (\%) & $23(20.9)$ & $13(11.8)$ & $19(17.4)$ & 0.459 \\
\hline
\end{tabular}


Table 2 Endoscopic examinations

\begin{tabular}{|c|c|c|c|c|}
\hline & Group $1(n=110)$ & Group $2(n=92)$ & Group $3(n=109)$ & $P$ value \\
\hline \multicolumn{5}{|l|}{ Endoscopic diagnosis, $n$ (\%) } \\
\hline Chronic atrophic gastritis & $6(5.5)$ & $4(4.3)$ & $10(9.2)$ & 0.607 \\
\hline Chronic non-atrophic gastritis & 89 (80.9) & $67(72.8)$ & $93(85.3)$ & \\
\hline Peptic ulcer & $5(4.5)$ & $7(7.6)$ & $3(2.8)$ & \\
\hline Polyp & $9(8.2)$ & $12(13.0)$ & $3(2.8)$ & \\
\hline Carcinoma & $1(0.9)$ & $2(2.2)$ & 0 & \\
\hline Biopsy, n (\%) & $43(39.1)$ & $59(64.1)$ & $55(50.5)$ & 0.289 \\
\hline \multicolumn{5}{|l|}{ Pathological diagnosis for biopsy, n (\%) } \\
\hline Chronic atrophic gastritis & $4(3.6)$ & $2(2.2)$ & $4(3.7)$ & \\
\hline Chronic non-atrophic gastritis & $22(20.0)$ & $18(19.6)$ & $36(33.0)$ & \\
\hline Peptic ulcer & $4(3.6)$ & $5(5.4)$ & $9(8.3)$ & \\
\hline Adenoma & $9(8.2)$ & $11(12.0)$ & $3(2.8)$ & \\
\hline Carcinoma & $1(0.9)$ & $2(2.2)$ & 0 & \\
\hline Intestinal metaplasia & $3(2.7)$ & $9(9.8)$ & $2(1.8)$ & \\
\hline High-grade intraepithelial neoplasm & 0 & $5(5.4)$ & 0 & \\
\hline Low-grade intraepithelial neoplasm & 0 & $7(7.6)$ & $1(0.9)$ & \\
\hline Examination time, min, median (range) & $8(2-20)$ & $6(2-15)$ & $9(2-25)$ & 0.267 \\
\hline Gastric Cleanness Grade, n (\%) & & & & $<0.001$ \\
\hline A & $19(17.3)$ & $73(79.3)$ & $29(26.6)$ & \\
\hline B & $19(17.3)$ & $12(13.0)$ & $41(37.6)$ & \\
\hline C & $72(65.5)$ & $7(7.6)$ & 39 (35.8) & \\
\hline
\end{tabular}

in this study, we aimed to investigate the influence of different simethicone administration strategies on the gastric cleanness for esophagogastroduodenoscopy.

Sajid MS et al. ever conducted a systematic review and meta-analysis of 7 randomized controlled trials on the application of simethicone in improving the gastric mucosal visualization during esophagogastroduodenoscopy [9]. These results supported that oral simethicone administration before endoscopic examinations can improve the mucosal visualization of the stomach. Mucosal visibility score was reported in four trials, and the other three trials reported the number of patients with adequate and poor visibility [10-16]. In our present study, we defined Gastric Cleanness Grade based on the observation of the water and foam in gastric body and fundus under endoscopy, which was manifested in Fig. 2. Gastric Cleanness Grade was used to evaluate the effectiveness of simethicone in cleaning the stomach for observation under endoscopy. Our data showed that the percentage of patients with Gastric Cleanness Grade A was highest in group 2 (simethicone solution intake 31$60 \mathrm{~min}$ before the procedure), which was obviously higher than those in groups 1 and 3 (79.3\% vs. $17.3 \%$ and $26.6 \%, P<0.001)$. It was proved that simethicone solution intake 31-60 min before the procedure can obtain the best gastric visualization for endoscopic procedures, compared with pre-procedural simethicone solution intake $20-30 \mathrm{~min}$ and $>60 \mathrm{~min}$ before.

Table 3 Satisfaction score (0-10) and discomfort after examinations

\begin{tabular}{|c|c|c|c|c|}
\hline & Group $1(n=110)$ & Group $2(n=92)$ & Group $3(n=109)$ & $P$ value \\
\hline \multicolumn{5}{|l|}{ Satisfaction score, mean (range) } \\
\hline Immediately after examination & $6(3-8)$ & $6(1-10)$ & $6(1-9)$ & 0.533 \\
\hline $2 \mathrm{~h}$ after examination & $10(8-10)$ & $10(10-10)$ & $10(8-10)$ & 0.463 \\
\hline \multicolumn{5}{|l|}{ Discomfort reported, $n$ (\%) } \\
\hline Abdominal distension & $38(34.5)$ & $23(25.0)$ & $29(26.6)$ & 0.264 \\
\hline Nausea & $13(11.8)$ & $8(8.7)$ & $6(5.5)$ & 0.252 \\
\hline Throat pain & $27(24.5)$ & $2(2.2)$ & $10(10.8)$ & $<0.001$ \\
\hline
\end{tabular}


No significant differences were found on patients' satisfaction score both immediately and $2 \mathrm{~h}$ after the procedure (both $P$ values $>0.05$ ), indicating that all the three simethicone intake methods were all tolerated by the patients. The incidence of symptoms reported by the patients was nearly comparable among different groups, except throat pain. Group 1 had a greatly higher percentage of patients $(24.5 \%, n=27)$ who had throat pain than 2.2\% $(n=2)$ in group 2 and $10.8 \%(n=10)$ in group $3(P<0.001)$. This may be partly explained by the repeated friction between endoscopy body and the pharyngeal mucosa in group 1 in order to remove the excessive water or foam in the stomach, which was consistent with the fact that the examination time in group 1 was a bit longer than that in group 2 but shorter than that in group 3 although the difference was not obviously significant [8 (2-20), $6(2-15)$, and $9(2-25) \mathrm{min}$; $P=0.267] .24 .5 \%$ patients in group 1 reported throat pain, which was greatly higher than those in groups 2 and 3. The difference of throat pain may be explained by the facts that individuals may have a different tolerance to the injury of throat mucosa caused by the manipulation of the endoscopy, and more patients with chronic pharyngitis were in group 1.

There were also limitations in this study. First, all the patients were included from one single center. Second, only selected demographic and clinical variables were analyzed here, and some other potential factors that may influence gastric mucosal visualization like dietary lifestyle were not investigated. Third, we did not examine the effect of simethicone combined with $\mathrm{N}$-acetylcysteine, because $\mathrm{N}$-acetylcysteine was not routinely used in our endoscopy center.

In summary, simethicone solution intake $31-60 \mathrm{~min}$ before the procedure is suggested, which can be introduced as a routine standard pre-procedural preparation for good quality esophagogastroduodenoscopy, especially for those patients with suspected malignant upper gastrointestinal lesions. Additionally, this conclusion will be further validated in a large multi-center randomized clinical trial.

\section{Acknowledgements}

Not applicable.

\section{Authors' contributions}

Xiaotian Sun, Yang Xu, and Xueting Zhang conducted the study and analyzed the data. Cuiyun Ma, Aitong Li, Haiyan Yu, Weihua Zhang, Hanqing Zhang, Teng Yang, Xinfang Miao, Huiming Zhang, and Yan Liu collected and categorized the data; Xiaotian Sun and Zheng Lu designed this study and wrote and revised the paper. All authors read and approved the final manuscript.

\section{Funding}

This work was supported by Beijing Municipal Natural Science Foundation (No.7214251, to Xiaotian Sun; No. 7192201 to Zheng Lu).
Availability of data and materials

Not applicable.

\section{Declarations}

Ethics approval and consent to participate

The protocol was approved by the ethic committee of Affiliated Hospital to Chinese Academy of Military Medical Sciences (the Fifth Medical Center of Chinese PLA General Hospital) on October 12, 2018. All the patients gave their written informed consent.

Consent for publication

Not applicable.

\section{Competing interests}

The authors declare that they have no competing interests.

\section{Author details}

${ }^{1}$ Gastrointestinal Endoscopy Center, The Fifth Medical Center of Chinese PLA General Hospital, Beijing 100071, China. ${ }^{2}$ Department of Internal Medicine, Beijing South Medical District, Chinese PLA General Hospital, Beijing 100161, China. ${ }^{3}$ Clinic of Fuxing Road, Beijing South Medical District, Chinese PLA General Hospital, Beijing 100161, China. ${ }^{4}$ Department of Hepatology, The Fifth Medical Center of Chinese PLA General Hospital, No. 100 Middle Road in Fourth West Ring, Beijing 100039, China.

Received: 3 April 2020 Accepted: 9 August 2021

Published online: 21 August 2021

\section{References}

1. Ebigbo A, Messmann H, Rommele C. Endoscopic upper Gl screening. Visc Med. 2019;35(4):240-4. https://doi.org/10.1159/000501889.

2. Emura F, Rodriguez-Reyes C, Giraldo-Cadavid L. Early gastric cancer: current limitations and what can be done to address them. Am J Gastroenterol. 2019;114(6):841-5. https://doi.org/10.14309/ajg.0000000000000220.

3. Dohi O, Majima A, Naito Y, Yoshida T, Ishida T, Azuma Y, Kitae H, Matsumura S, Mizuno N, Yoshida N, Kamada K, Itoh Y. Can image-enhanced endoscopy improve the diagnosis of Kyoto classification of gastritis in the clinical setting? Dig Endosc. 2020;32(2):191-203. https://doi.org/10.1111/den.13540.

4. Swager AF, van der Sommen F, Klomp SR, Zinger S, Meijer SL, Schoon EJ, et al. Computer-aided detection of early Barrett's neoplasia using volumetric laser endomicroscopy. Gastrointest Endosc. 2017;86(5):839-46. https://doi. org/10.1016/j.gie.2017.03.011

5. Mori Y, Kudo SE, Mohmed HEN, Misawa M, Ogata N, Itoh H, et al. Artificial intelligence and upper gastrointestinal endoscopy: current status and future perspective. Dig Endosc. 2019;31(4):378-88. https://doi. org/10.1111/den.13317.

6. Devereaux BM, Taylor ACF, Athan E, Wallis DJ, Brown RR, Greig SM, Bailey FK, Vickery $K$, Wardle E, Jones DM. Simethicone use during gastrointestinal endoscopy: Position statement of the Gastroenterological Society of Australia. J Gastroenterol Hepatol. 2019;34(12):2086-9. https://doi.org/1 $0.1111 /$ jgh. 14757

7. Ofstead CL, Hopkins KM, Eiland JE, Wetzler HP. Widespread clinical use of simethicone, insoluble lubricants, and tissue glue during endoscopy: a call to action for infection preventionists. Am J Infect Control. 2019;47(6):666-70. https://doi.org/10.1016/j.ajic.2019.02.012.

8. Bhandari P, Subramaniam S, East JE. British Society of Gastroenterology Endoscopy Quality Improvement Programme (BSG EQIP): implementing new endoscopic techniques and technologies into clinical practice. Frontline Gastroenterol. 2019;10(2):155-9. https://doi.org/10.1136/flgastro-2 018-101074

9. Sajid MS, Rehman S, Chedgy F, Singh KK. Improving the mucosal visualization at gastroscopy: a systematic review and meta-analysis of randomized, controlled trials reporting the role of Simethicone $\pm \mathrm{N}$ acetylcysteine. Transl Gastroenterol Hepatol. 2018;3:29. https://doi.org/10.21 037/tgh.2018.05.02.

10. Asl SM, Sivandzadeh GR. Efficacy of premedication with activated Dimethicone or $\mathrm{N}$-acetylcysteine in improving visibility during upper endoscopy. World J Gastroenterol. 2011;17(37):4213-7. https://doi.org/10.374 8/wjg.v17.i37.4213 
11. Basford PJ, Brown J, Gadeke L, Fogg C, Haysom-Newport B, Ogollah R, et al. A randomized controlled trial of pre-procedure simethicone and $\mathrm{N}$-acetylcysteine to improve mucosal visibility during gastroscopy NICEVIS. Endosc Int Open. 2016;4(11):E1197-202. https://doi.org/10.1055/ s-0042-117631.

12. Keeratichananont S, Sobhonslidsuk A, Kitiyakara T, Achalanan N, Soonthornpun S. The role of liquid simethicone in enhancing endoscopic visibility prior to esophagogastroduodenoscopy (EGD): a prospective, randomized, double-blinded, placebo-controlled trial. J Med Assoc Thai. 2010;93(8):892-7.

13. Song M, Kwek AB, Law NM, Ong JP, Tan JY, Harichander Thurairajah P, et al. Efficacy of small-volume simethicone given at least 30 min before gastroscopy. World J Gastrointest Pharmacol Ther. 2016;7(4):572-8. https:// doi.org/10.4292/wjgpt.v7.i4.572

14. Ahsan M, Babaei L, Gholamrezaei A, Emami MH. Simethicone for the preparation before esophagogastroduodenoscopy. Diagn Ther Endosc. 2011;2011:484532.

15. Elvas L, Areia M, Brito D, Alves S, Saraiva S, Cadime AT. Premedication with simethicone and $\mathrm{N}$-acetylcysteine in improving visibility during upper endoscopy: a double-blind randomized trial. Endoscopy. 2017;49(2):139-45. https://doi.org/10.1055/s-0042-119034

16. Monrroy H, Vargas Jl, Glasinovic E, Candia R, Azúa E, Gálvez C, et al. Use of $\mathrm{N}$-acetylcysteine plus simethicone to improve mucosal visibility during upper $\mathrm{Gl}$ endoscopy: a double-blind, randomized controlled trial. Gastrointest Endosc. 2018;87(4):986-93. https://doi.org/10.1016/j.gie.201 7.10.005.

\section{Publisher's Note}

Springer Nature remains neutral with regard to jurisdictional claims in published maps and institutional affiliations.

Ready to submit your research? Choose BMC and benefit from:

- fast, convenient online submission

- thorough peer review by experienced researchers in your field

- rapid publication on acceptance

- support for research data, including large and complex data types

- gold Open Access which fosters wider collaboration and increased citations

- maximum visibility for your research: over $100 \mathrm{M}$ website views per year

At $\mathrm{BMC}$, research is always in progress.

Learn more biomedcentral.com/submissions 